\title{
Analysis of the Impact of ICT on Sustainable Development using Sustainability Indicators
}

\author{
Mohammad Azadnia \\ Faculty member and Head \\ of IT lab, ICT Research \\ Center \\ Tehran, Iran
}

\author{
Shamsossadat \\ Zahedi \\ Faculty member and \\ Professor of Allameh \\ University \\ Tehran, Iran
}

\author{
Abdorreza Majjedin \\ Head of Institute of \\ Applied Science \\ Technology \\ Tehran, Iran
}

\author{
Mohammad Reza \\ Pourabedy \\ Deputy of Research and \\ Technology \\ Tehran, Iran
}

\begin{abstract}
The aim of this study has been the investigation of the effect of ICT on sustainable development in the geographic area of Iran using sustainability indices. After defining and providing a brief description of the areas of sustainable development and ICT, and identifying the indicators in order to measure them, the popular models in these two areas were introduced in this study. Reviewing the previous studies on this issue has been followed. The proposed conceptual model in order to investigate the interaction of these two areas were considered with regard to the sustainability indices which have been derived from valid international sources, theoretical studies, and expert advices in these two areas. Using quantitative methods and a refined structured questionnaire, this model calculated weight and the effect of each of the categories, and finally the analytical framework was presented. The heuristic and the librarian methods were employed to identify the problem, and to investigate the former information and records respectively in this study. Finally, the main factors to explain and design the basic model were identified through interviews with experts. The quantitative method was used for the verification and validation of the model. According to the presented model, the degree and the effect of ICT dimensions on sustainability indicators were identified. In general, it can be concluded that ICT development will promote most indicators of sustainability. For each indicator alone the degree of effect has been identified.
\end{abstract}

\section{General Terms}

Information Technology, Environment, Communication Technology, Development, Conceptual Model

\section{Keywords}

Measurement Model, ICT, Sustainable Development, Index, Sustainability

\section{INTRODUCTION}

The world faced two unanticipated problems of the broad environmental degradation and the spread of poverty and inequality with the current rapid growth of developing countries particularly after World War II. Since then ever the definitions of the development have been revised with a focus on addressing these two problems.

Social, economic, and environmental problems are visible in different forms in our country. Illiteracy, poverty, unemployment, pollution, dust, and forest degradation and problems of this kind have affected people's lives. These problems are in the wider circle of cases in which sustainable development is considered to deal with them.

Information and Communication Technology (ICT) is one of the important branches of science and technology which can play an effective role in modulating these effects. ICT has considerable influence on most modern societies and perhaps imagine life without it is impossible in the present century.

In this study, the aim was to identify models and indicators of ICT development and sustainable development and its dimensions. Theoretical studies were performed at first for this purpose. Various models of ICT development and sustainable development as well as model that showed the interaction of these two areas were investigated in these studies. Then the records and previous studies on the subject were discussed and reviewed. These studies had two important shortcomings. First, a study which takes into account all three dimensions of sustainable development was not seen. Second, a study were generally conducted at the global level or in a set of countries and no special study was found to address Iran using sustainability indicators in history and literature.

\section{SUSTAINABLE DEVELOPMENT AND ICT}

Issues of economic, social, and human development and combining it with environmental development provide a new paradigm in development, a development which emphasizes inter-generational and intra-generational equity and social justice and environmental protection considers as one of its main axis. This new paradigm which is called the paradigm of sustainability and sustainable development has several dimensions that environmental, economic, and social aspects are considered as the most important dimensions. Sustainable development has many aspects of which the most important ones are listed below.

Endangering the animate species, destruction of forests and pollution of air and water, quantity or amount of energy used, and the use of hazardous materials are considered as the perspective of sustainable development from environmental aspects. A system of environmental sustainability should support the vital sources, and avoid the improper use of nonrenewable resources as well as functions that lead to environmental degradation.

Economic aspects are different from financial aspects. The financial aspects associated with positive financial balance sheets and the ability of an organization to human or environmental needs, however the economic aspects is beyond the balance sheet and includes items such as global poverty, the impact of the economy on trade, investment and wealth distribution, and GNP and GDP. A stable economic system must produce goods and services which prevent the imbalance of population in different economic sectors and does not damage the agricultural and industrial production. 
Social dimension is related to human and includes human rights. To have equal access to education and health or human exploitation and abuse are related to this dimension. A stable social system should achieve equitable distribution of resources and social facilities including health, education, gender equality, political accountability and participation [1].

Sustainable development, a multi-faceted notion with different dimensions, has two-way interactive communication which includes spiritual development, human development, social development, cultural development, political development, and economic development in other view. Energy resources, natural resources, vital resources are considered as environmental sustainable development resources. Social capital (including institution-building and social cohesion) and social dynamics are considered as the social components of sustainable development. Finally, labor, capital, technology, and information which are the infrastructure of GDP can be considered as economic components of sustainable development [2].

\subsection{Sustainable Development Models}

Some patterns of sustainable development are as the following. Given the considerable differences in their appearance, almost all of them base sustainable development on the three pillars of the environment, economy and society. These models include:

1. The tripod model of sustainability in which sustainable development has been based on three pillars of social, economic, and natural environment.

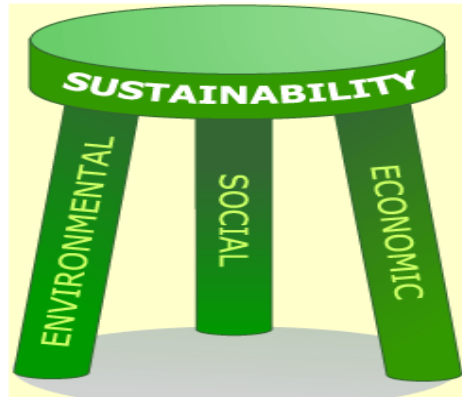

Fig. 1: The tripod model of sustainability

2. The three-sphere model which based the realization of sustainability on the realization of three dimensions of society, economy and environment.

Environmental, social, and economic developments have always been emphasized in different models of sustainable development. However, in addition to the above dimensions the political dimension and other cases are considered in some of them.

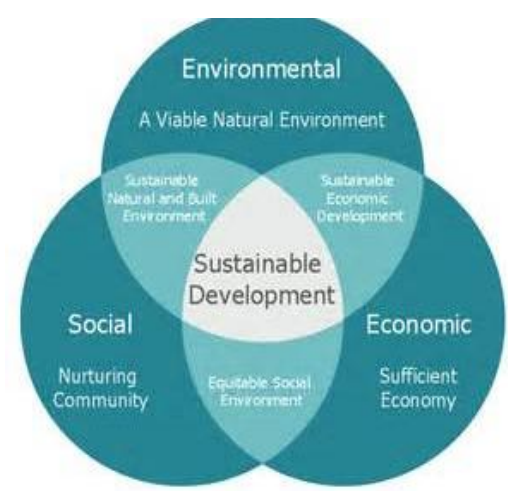

Fig. 2: Three-sphere model

\subsection{Information and Communication Technology (ICT)}

IT addresses issues such as the use of electronic computers and software so that the store, process, transfer, convert, protect, and recovery of data be safely carried out. The effect of ICT in public administration (such as urban and rural development, transport), improve the quality of life (such as health, education, environment, agriculture), knowledge sharing and improve access to information, the use of ICT in business (such as manufacturing, electronic commerce, tourism, and travel industry) is obvious.

In addition, topics such as health, careers, business, security, the environment, regional development, human rights, and education are affected by ICT; while in many cases, this connection can be two-way.

ICT can have positive and negative effects on sustainable development. On the one hand, the sustainable development can be realized with a higher efficiency and effectiveness through ICT, on the other hand, ICT also can be an obstacle to the realization of sustainable development as a product (or service) or as a tool to empower other sectors.

\subsection{ICT Development Models}

There are various categories for ICT development models. In one category, these models are divided into general models, special models (domain), and in another category they are divided into micro and macro-level models and in another place these models are divided into functional and nonfunctional (non-performance) models [3].

ICT development model is the most appropriate and most comprehensive model for IT architecture, and is appropriate to investigate the relationship of ICT and sustainable development. Firstly, this model is of good integrity and includes principal component of sustainable development in social, economic, environmental, and policy dimensions, and secondly is of high coordination with sustainable development aspects.

As shown in Figure 3, three-axis of development, technological infrastructure, and ICT services have been used in order to categorize the issues raised in this area in the threedimensional model of the development of ICT. Technological infrastructure axis includes ICT-based research, ICT access, trust and general security, ICT skills and learning, electronic content, and infrastructure. ICT governance and policy making and ICT coordination included in strategic sector and finally, the axis of ICT services includes e-business, ICT industry, security, government and public services, e-health, and e-learning. [3]

The aforementioned conceptual model represents the inseparable relationship between different parts ranging from application, development strategy, and empowerment in the ICT development process. 


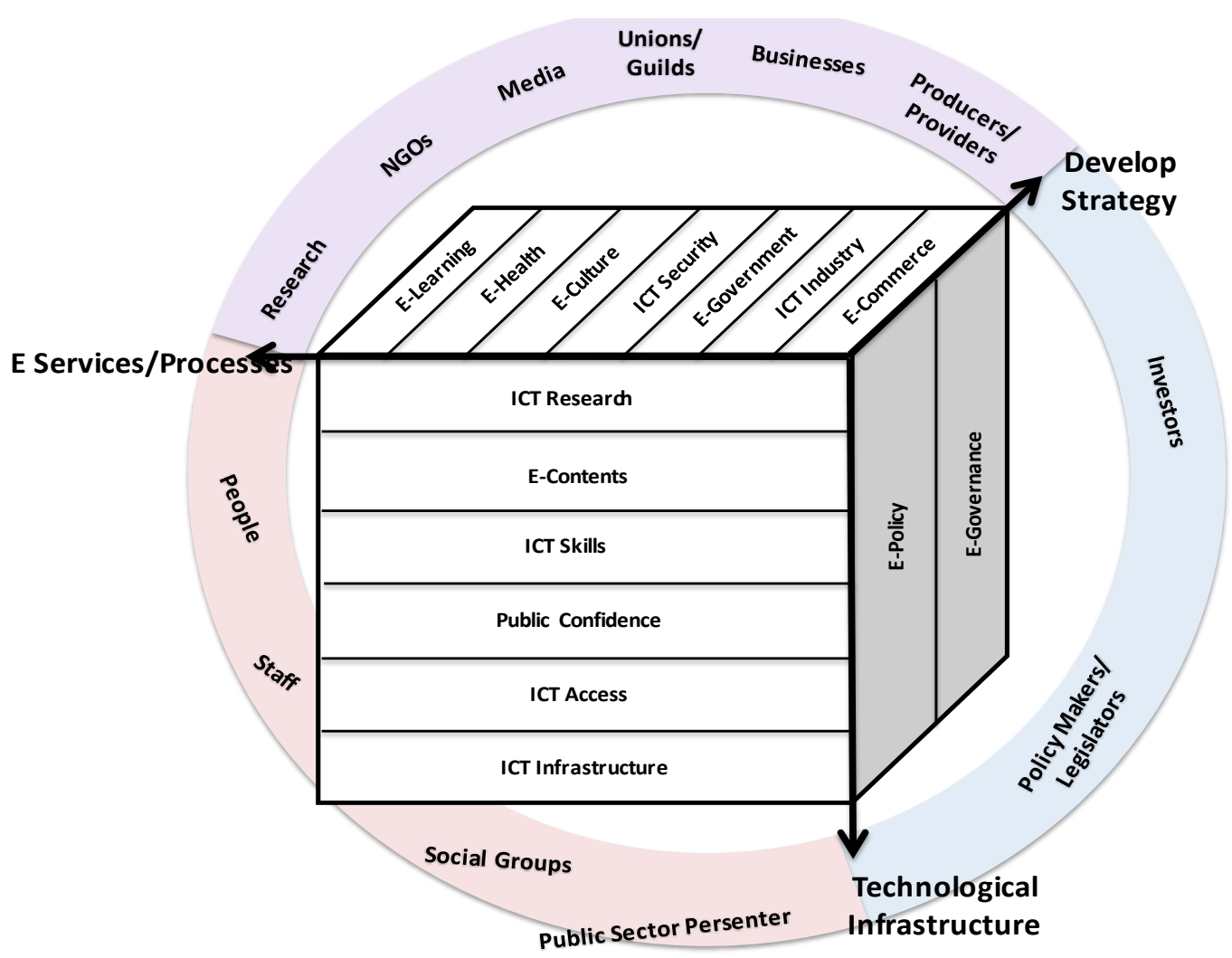

Fig. 3: Conceptual model of ICT structure development

\subsection{Interaction of ICT and Sustainable Development Dimensions}

This study aims to investigate the effects and assess the impact of ICT on sustainable development in this study. First, there's a review on the studies in this field, and then the components and dimensions are extracted in each of the concepts and their relationships are investigated. Finally, a model for measuring these effects is presented. This model will be useful for planning and macro decision-making in the development of ICT.

\subsubsection{The Status and Role of Models and Indicators of the Impact of ICT and Sustainable}

Development Models

The conceptual model of ICT represents its covering on the areas including aspects and the main components of sustainable development. Therefore, it has undeniable effects on sustainable development (environment, economy and society) which will be discussed below.

ICT has considerable influence on most of modern society issues. Along with the increase of pollution caused by economic development and growth of consumption, the use of information and communication technologies in developing countries in comparison with other countries could decrease the growth of pollution and improve the quality of the environment. [4]

IT reduces the need of communities to natural substances in the environment. It also reduces the amount of waste entering the environment [5].

\subsubsection{The Impact of ICT on the Environment}

The relationship between information and communication technologies and the environment is one of the complex and multi-dimensional issues. ICT can have both positive and negative effects on the stability of the environment. ICT is a powerful tool for communities to protect the environment. The facilities which ICT provide for human communication reduce the need of communities to natural substances in environment.

It also reduces the amount of waste entering the environment. On the other hand, production and distribution of ICT facilities require energy and materials and due to the short life cycle of ICT facilities, electronic waste entering the environment is increasing [5].

With regard to the impact of information and communication technology on environment, this issue can be investigated from different aspects, since examples and consequences of using this technology in various aspects of human life are obvious and can be investigated. The effects of information and communication technology on the environment are divided into three separate categories as follows:

\section{(a) First Category (Level One)}

Those consequences (outcomes) of environmental information and communication technology are investigated at this level which solely caused by the production and use of the facilities in this field which are called direct consequences and are divided into two groups of positive and negative consequences. Negative consequences include those parts of environmental consequences that are obtained from the production process of ICT such as computer hardware, network cables, monitors, consequences of disposal and destruction of ICT facilities, etc. Positive effects include 
capabilities that are obtained from production and supply of ICT products. For example, electronics indicator of pollution, electronic controls, and more.

(b) Second Category (Level Two)

At this level, that part of the environmental effects of ICT (such as the use of ICT in the process of production, distribution, and consumption) is considered which influence macroeconomic sectors in terms of virtualization and increasing access among economic agents.

\section{(c) Third Category (Third Level)}

This level is related to stimulation and motivation on the part of the effects of information and communication technology goes which makes the channel of higher economic growth, taking the total economy (as compared with the case where the information and communication technology is not used) increase which are famous as reaction and restoration effects. It is necessary to mention that the relative size of each of these effects (in three categories mentioned) is not equal and no doubt what is posed in the form of the consequence of the use of information and communication technology in the second level is far more impressive than the other two levels [6].

The divisions of positive and negative effects of ICT on the environment are shown in Table 1.

\subsubsection{The Effect of ICT on the Economy}

This section aims to investigate the use of information and communication technology ICT on economic growth. The results of a study show that information and communication technology has a positive and significant effect on economic growth in the countries surveyed (selected developing countries). In other words, greater use of information and communication technology in the production process increases economic growth in the countries surveyed including Iran [7].

Investigation of global economic developments over recent decades indicates the key difference of these developments compared to past which most of these differences related to the revolution that has occurred in these decades. Studies indicate that information and communication technology in 1965 has allocated about 5 percent of the cost of investment of companies, this figure rose to $15 \%$ in $1980 \mathrm{~s}$ and the company's information technology investment costs in the early 1990 s rose to $20 \%$ and at the end of the 1990 s and the threshold of the third millennium has increased to $50 \%$ of investment costs [8]. Information and communication technology in the economy influences both the supply side and the demand side. On the demand side through utility function influences the economic behavior of the consumer and on the supply side influences the manufacturer behavior [9].

Experience has shown that usually the countries which have more accumulation of capital in the information and communication technology grow faster than countries that have less accumulation of capital in this sector [10].

\subsubsection{The Effect of ICT on Society}

The social dimension of sustainable development is concerned with the relationship between man and woman, excellence well-being, health and educational services, the development of different cultures, and equality and poverty eradication. Economists also explain the role of the social systems in achieving sustainable social development process to help the two principles of "human capital" and "social capital".
The foresight and responsibility towards future generations and their needs, public health, and attention to the health and quality of life, social justice, popular participation and emphasis on the sense of collectivism and transparent decision-making and education of people can be noted in the social dimension of sustainable development. The sustainable community is not only interested in quantitative and physical but also interested in qualitative development in this concept, it also focuses on the development of quality and look for stable process of life for the present generation and generations to come.

The development of ICT in education programs is significant and lasting steps which can be followed by qualitative transformation of objectives, programs, methods, practices and thus the effectiveness of education. It is anticipated that longstanding policies and intractable problems, such as the applied education issues, focusing on the abilities and needs of learners, establishment of student-centrism rather than class-centrism and changing the role of the teacher as a guide for students, and finally authenticating lifelong learning will be achieved through the development of ICT; However, what is constituting educational thinking within this missing link and paying attention to it is important is to focus on positive and negative application of information and communication technology in the education system [11].

\subsection{Interactive Models of ICT}

Numerous models have been proposed with regard to the interaction of ICT and sustainable development. The three examples of the most valid ones followed.

Table 1. Classification of positive and negative effects of ICT

\begin{tabular}{|c|c|c|}
\hline Negative effect & Positive effect & \\
\hline $\begin{array}{c}\text { The } \\
\text { environmental } \\
\text { impact of } \\
\text { production and } \\
\text { use of ICT, such as } \\
\text { e-waste }\end{array}$ & $\begin{array}{c}\text { The use of ICT, such } \\
\text { as the use of ICT for } \\
\text { environmental } \\
\text { monitoring and } \\
\text { control }\end{array}$ & $\begin{array}{c}\text { The first } \\
\text { type effect } \\
\text { or direct } \\
\text { effect }\end{array}$ \\
\hline $\begin{array}{c}\text { Non-complete } \\
\text { substitution of } \\
\text { ICT for other } \\
\text { materials }\end{array}$ & $\begin{array}{c}\text { Restructuring to the } \\
\text { non-material }\end{array}$ & $\begin{array}{c}\text { The second } \\
\text { type effect } \\
\text { or indirect } \\
\text { effect }\end{array}$ \\
\hline $\begin{array}{c}\text { The reflection or } \\
\text { return effect }\end{array}$ & $\begin{array}{c}\text { Lifestyle changes } \\
\text { such as guiding } \\
\text { consumers towards } \\
\text { green consumption }\end{array}$ & $\begin{array}{c}\text { The third } \\
\text { type effect }\end{array}$ \\
\hline
\end{tabular}

\subsubsection{Measurement Model of the Effects of Information Society}

This model has been proposed by the OECD in 2007. As seen in Figure 4, the effects of the information society are presented in two ways. A series of effects from the demand side (users and applications) that their purpose includes government (through the development of e-government), individuals and households (through health and e-learning), and business (through e-commerce).

The second set is the effects of the supply dimension (production and products) that are concerned with society, economy, and environment. The content includes media and products which are produced in different parts of ICT. 


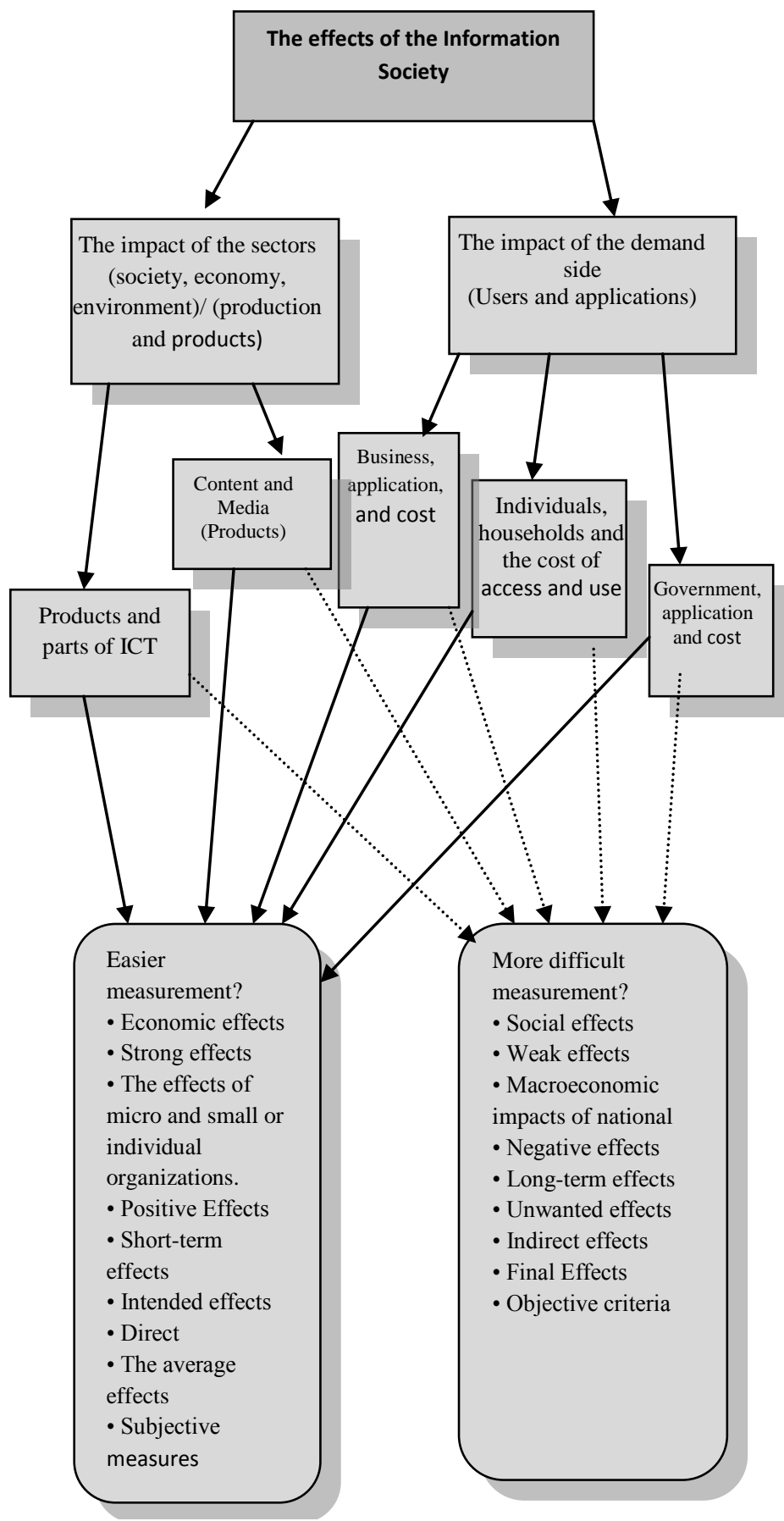

Fig. 4: Conceptual model of the information society [6]

\subsubsection{UNCTAD Model}

The next model that has been developed by UNCTAD (Figure 5) shows the relationship between the effects of ICT. In this model, the positive and negative aspects of impacts of ICT which is created through supply and demand of ICT have been shown.

This model suggests that the effects of ICT in the fields of economy, society, and the environment show themselves. These effects are formed for ICT through supply and demand and are influenced by the following factors:

- Available ICT infrastructures

- The level of education, skills, income

- Regulations and government policies on ICT and egovernment development

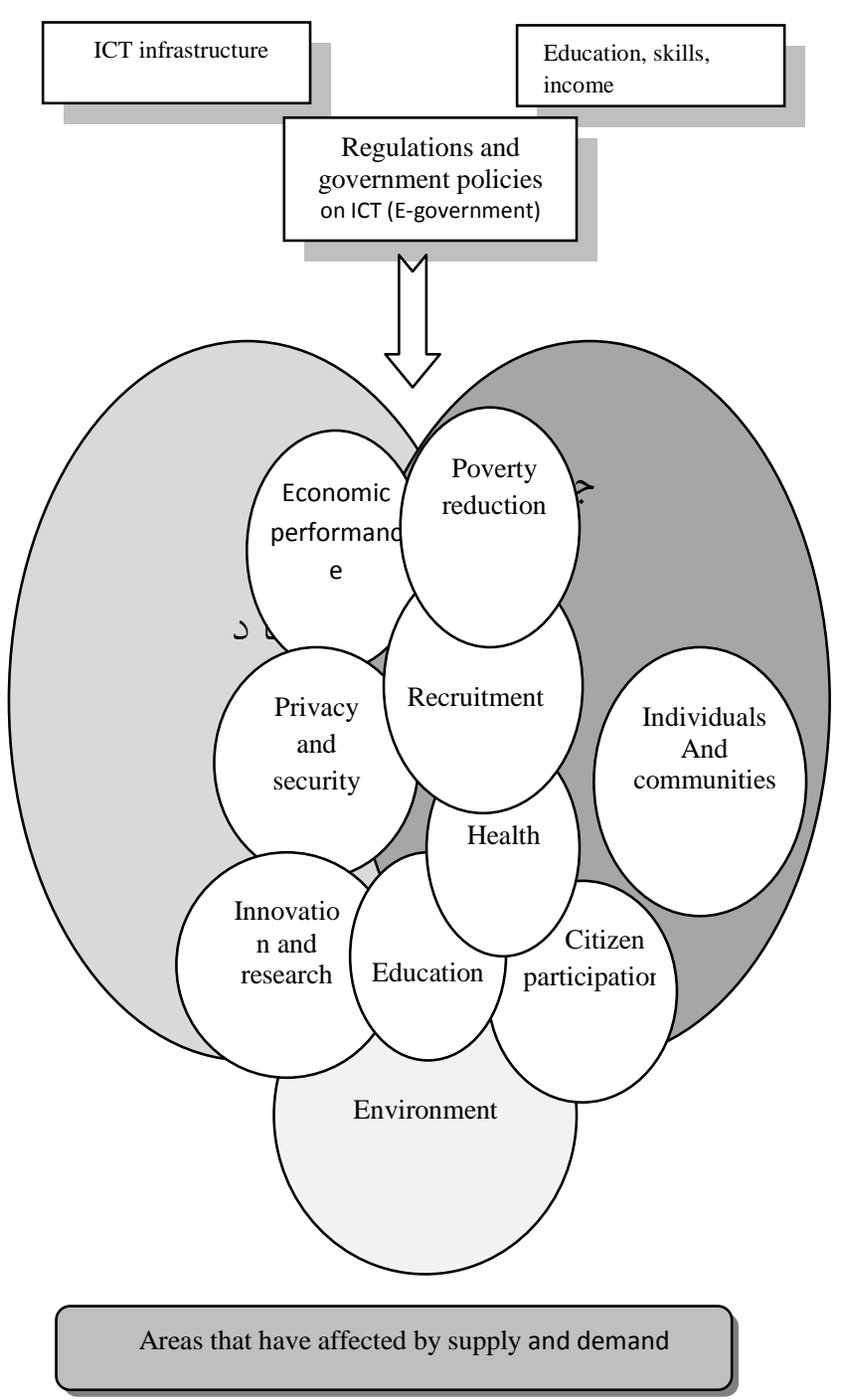

Fig. 5: UNCTAD model: the relationship between the effects of ICT

\subsubsection{The Conceptual Model of the Effects of ICT on the Environment of Economic Cooperation and Development $(O E C D)$}

Another model proposed by the OECD was consistent with the two previous models and is a complement to them. In the preceding models, the environment has attracted less attention. Recent model like the two preceding models separates the effects of ICT on both the supply (goods, services) and demand (users and applications), and infrastructure, content, and media are of the mediating influence.

This model indicates that supply and demand of IT affect the environment each way. That is, we have the combination of the effects of ICT supply and demand of ICT on the environment. On the other hand there are a series of indirect effects of ICT on environmental which can be reviewed and discussed.

1. The effects of the supply of ICT on the environment More of these effects are due to the supply of ICT products such as computer and its auxiliary equipment, telecommunication equipment, consumer electronics, products and accessories of ICT, construction of ICT equipment 
services, commercial software, consulting ICT services, telecommunication services, and telecommunication leased lines and the other ICT services, etc.

2. The effects of ICT demand on the environment Some of the effects of ICT on the environment demand include:

(a) The effects of the use of ICT in improving environmental outcomes such as: efficiency, monitoring, modeling, managing, and publishing

(b) The effects of the use of ICT which is leading to environmental damages such as energy consumption, pollution caused by the destruction of outdated equipment

\section{Indirect effects of ICT on the environment}

Promotion and development of knowledge through facilities caused by ICT (content and media) are of indirect effects of ICT on the environment.

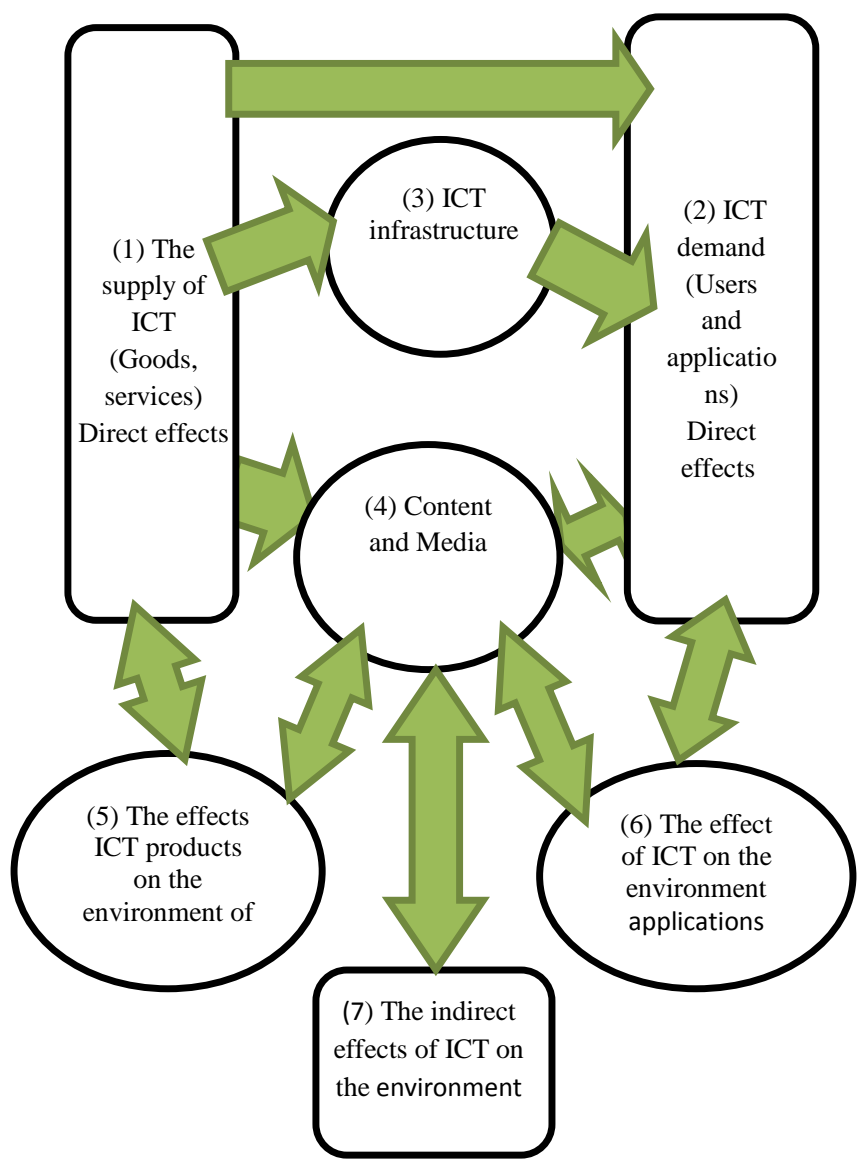

Fig. 6: Conceptual model of the effects of ICT on the environment [6]

\section{A REVIEW OF CONDUCTED STUDIES}

There are different views to investigate and summarize the conducted studies. One method is to investigate the studies based on the date they have carried out that has its own advantages. This method allows us to study the evolution and development of the topic. The next view is to divide the conducted studies into internal and external. The comparison of internal and external investigations will be easier in this method. The third method was to classify studies based on the themes and its benefits are the ability to focus on different areas of research. In this study, according to the breadth of topics of ICT and sustainable development, the consolidated view with a focus on topics was selected. That is, in the first place studies were divided into the three axis of the effect of information and communication technology on economic growth, the effect of economic growth on the quality of the environment, and information and communication technology on the environment and in the second place with regard to the chronological order in each group of domestic studies and foreign studies will be considered separately.

The First group: In this group of reviews, the effect of information and communication technology on economic growth has been investigated

Some foreign studies conducted in this group are as follows.

Oliner and Sichel [12] investigate the qualitative and quantitative research on the role of information and communication technology in economic growth in developing and developed countries and suggest that there is a strong positive relationship between information and communication technology ICT and economic growth in developed countries. The use of ICT has led to changes in labor composition in favor of skilled workers who are fluent in information and communication technology skills.

Nour [13] in his study which was conducted in Egypt and other Arabic countries of the Persian Gulf argues that ICT in most cases has a positive correlation with economic growth, that is, economic growth increases by increasing investment in ICT and increasing the use and application of it.

Dewan and Kraemer [14] investigate the effect of ICT capital in developing and developed countries in their study and conclude that ICT investment yields is positive and significant in developed countries and is not significant in developing countries.

Lee and Kateri [15] have investigated the effect of ICT on economic growth in Southeast Asia in their study. They conclude that the effect of ICT on economic growth started from capital deepening of the ICT sector in the 1990s and capital deepening of the ICT sector plays a major role in improving labor productivity in studied countries in the second half of the twentieth century.

Dewan and Kraemer [14] through using the data of 36 countries during the period 1982-3 in both developed and developing countries estimate the effect of information and communication technology on economic growth. This estimation shows that the elasticity of information technology in developing countries equals the negative of 0.012 and 0.057 in developed countries.

Papaioannou [16] has investigated the effects of ICT on economic growth in developing and developed countries for the period 1993-2001 in his study and find an insignificant positive relationship between the effect of information and communication technology on economic growth and productivity for all countries under study.

Oulton and Srinivasan [17] through using new data sets in the industry level to quantify the role of information and communication technology in the productivity growth in the UK during the years 1970-2000 for 34 industries came to the conclusion that it is very important to invest in ICT and its role in economic growth is increasingly enhanced.

Ketteni [18] through studying the relationship of information and communication technology on productivity and economic 
growth has shown that the total investment in information and communication technology has a nonlinear effect on growth factor total productivity.

Mouelhi [19] with the aim of measuring the effect of ICT on total productivity of production of some companies in Tunisia in a simple theoretical framework has studied and investigated the relationship between these two categories through using data panel and approved a positive relationship between them.

Lee and Kateri [15] have investigated the effect of ICT on economic growth in Southeast Asian countries. The studies of these two show that the assistance of information and communication technology to economic growth has begun since the 1990s.

In these countries in recent years, costs are high in the field of software development, and the increase of costs of information and communication technology in these countries has helped to control the East Asian crisis in the 1990s. High growth in demand for electronic industry in 1990s is mentioned as the most important factor in this regard. The results of this study show that in the second half of 1990, capital deepening played an important role in improving labor productivity in Asian countries. Although in the first half of 1990s capital deepening in information and communication has assisted labor productivity which have been more significant in several countries such as Hong Kong, Singapore, and South Korea. But these contributions were higher in the second half of 1990s and led to acceleration of investment in communication and information technology. However, high levels of cost of communication and information technology were reduced due to the crisis in East Asia in this period. During the above periods, regarding capital deepening due to the high income share of communication and information technology Hong Kong, Korea, and Singapore gained more interest. In the Philippines in the second half of 1990s the communications and information technology makes more capital deepening and help to economic growth and makes that economic growth does not change or in other words, at least creates the lowest effect of the East Asian crisis in this period.

According to the study of Nour [13], in the case of Egypt and some Persian Gulf Arab countries cost of information and communication technology in most cases has a positive correlation with economic growth (GDP). Nour [13] in his study in Egypt and 16 Persian Gulf Arab countries states that the effect of the cost of information and communications technology in economic development in Egypt and the Arab countries of the Persian Gulf, in most cases, has a correlation with economic growth of GDP. However, their econometric studies which have investigated the expenditure of information and communication technology in the GDP of these countries in the period 1996-2001 show that the significant effect of information and communications technology on economic growth in Egypt and Persian Gulf Arab countries is obscure and suspicious. In general, information and communications technology in these countries has positive effect; however, its significance is obscure and suspicious.

Asari Arani and Aghei Khoundaei [20] examined the effect of information technology on economic growth in APEC member economies. Through using the Cobb-Douglas Production Function and with regard to variable of information and communication technology and Data Panel, they concluded that a strong and significant relationship between information and communication technology and economic growth has existed in this country since 2004 .

In Iran, some investigations have been done in this area. In part of the studies the effect of Internet on the export of the selected countries was investigated. Some other studies have investigated the effect of ICT on employment in the service sector in Iran and other groups have tried to estimate the share of ICT on economic growth in different intervals.

Najarzadeh, Aghaei Khoundaei and Talati [21] have investigated the effect of information and communication on economic growth of Organization of Islamic Cooperation (OIC) countries. They made use of investment data and information and communication technology in the period 1996-2004 and analyzed using data panel method. The result indicated that there is a strong and significant relationship between economic growth and information and communication technology in these countries.

Asgharpour, Mohammad Zadeh and Jalilpour [22] have investigated the effect of the development indices on adoption of information and communication technology in selected Asian countries. Their results showed that geographical and regional differences along with some of the indicators of development can to a large extent explain the differences in the use of information and communication technology in the countries studied.

Moshiri and Jahangard [9] have investigated the effects of ICT on growth and productivity of Iran economy. The results indicate the existence of a positive but insignificant and weak relationship between economic growth and information and communication technology in Iran by 1380 .

Faghih Nasiri and Goudarzi [23] investigated the effects of information and communication technology on economic growth of 37 developed countries in their study, the results of this study showed that the cost of information and communication technology is of great importance in the economic growth of the country.

The results of a study show that information and communication technology on economic growth in the countries surveyed (selected developing) has a significant positive effect. In other words, greater use of information and communication technology in the production process increases the economic growth in the countries surveyed including Iran [7].

According to the aforementioned research and numerous opinions offered by scholars, it seems ICT is of great importance in the economic growth of these countries in developing countries, but there is no strong and lasting relationship between information and communication technology and economic growth in developing countries.

The second group: In the second group the effect of economic growth on the quality of the environment is studied. Some of the studies in this area include:

In Iran, the research has been conducted about the effects of economic growth on the environment which the first study in this field of Pajooyan and Moradhasel entitled investigating the effect of economic growth on air pollution in the form of environmental curves of Kuznets for 67 countries [24]. However, other work has been done in this field after this study. For example Pour Kazemi and Ebrahimi [25] investigated the relationship between income and the release of sulfur dioxide for Middle Eastern countries over the period 1980 to 2003 in a study and in another study Asgharpour and 
Mousavi [26] investigated the relationship between air pollution and economic growth (testing environmental hypothesis of Kuznets) in 16 selected developed and developing countries including Iran.

The Third group: The third group of studies includes the studies in which the effect of information and communication technology on the environment is studied. Among foreign studies carried out on this group, the following can be cited:

Plepys [27] in his study investigates the effects of information and communication on the environment with a negative attitude. This means that if the management of production process and disposal of ICT hardware products is not done carefully, it can have serious environmental consequences. In a way that in some cases, it affects positive consequences. [28]

Yi and Thomas [29] in their article that reviews the studies carried out in the field of effects of information and communication technology and e-business on the environment investigated all available studies including: articles, research projects, dissertations, etc. They claim that both the case studies have been done on the micro level and studies on the macro level and in the form of a statistical approach has been done, yet full convergence on the apparent effect of ICT on the process of sustainable environmental is not met. [28]

A specific study to assess the effect of information and communication technology on the quality of the environment is not observed within the country. A review of studies on the use of ICT is still impossible to express a judgment on the sustainability of the environment and conducting new studies and new methods are also needed.

In comparison of the relative effect of the function of information and communication technology in two groups of countries, it can be seen that the positive effect of information and communication technology on (reducing) the quality of the environment in developing countries (Asian) is negligible. However, this effect in developed countries has emerged as significant and positive which is remarkable. This can be due to the institutionalization and maturity of information and communication technology in developed countries.

Studies conducted on the effect of ICT on aspects of sustainable development show that the impact of ICT in this regard has not been the same for all countries. In general, it can be concluded that with regard to the environmental developed countries, weaker effects have been observed. However, different results are obtained for developing countries, as there have been considerable effects on the social dimension and less effective or suspected economic dimensions have been reported and no positive effect on the environment.

Iran is now among developing countries. According to studies which have been reviewed, it can be predicted that the model presented in this study shows the effects of ICT on the development of social sustainability indicators with the highest value. Second, economic indexes have been influenced and finally the least effect was shown on environmental sustainability indexes.

\section{METHODS}

Different stages have been considered in the present study, the type of the research (based on the classifications listed) will be different at each stage. In short, the type of research in different phases of research considering three axes is shown in table 1 .

As mentioned, a mixed strategy was used in order to conduct this study. In other words, two studies were conducted in order to investigate research questions, one with quantitative value and the other with qualitative approach. In general, the heuristics methods were used for exploration, the library method for background information and research literature. Qualitative methods used to identify the main factors in terms of population and quantitative methods were used to measure the main factors in order to reach the final model.

Table 1. Status of current research

\begin{tabular}{|c|c|c|}
\hline $\begin{array}{c}\text { third stage } \\
\text { Quantitative } \\
\text { analysisof mode }\end{array}$ & $\begin{array}{c}\text { first stage } \\
\text { Qualitative } \\
\text { analysis of } \\
\text { model }\end{array}$ & The classification \\
\hline Explanatory & Heuristic & $\begin{array}{c}\text { The aim of the } \\
\text { study }\end{array}$ \\
\hline Applied & Fundamental & $\begin{array}{c}\text { The result of the } \\
\text { study }\end{array}$ \\
\hline Quantitative & Qualitative & $\begin{array}{c}\text { The data of the } \\
\text { study }\end{array}$ \\
\hline
\end{tabular}

Integrated policy used in this study is called "exploratory stage". This policy has two stages. The collection and analysis of data qualitative is done in the first step of this policy and relying on early quantitative the collection and analysis of quantitative data is done. [30]

The population consisted of 12 scientific and professional experts in qualitative section. They have been selected by the researcher through consultation with supervisor and advisor.

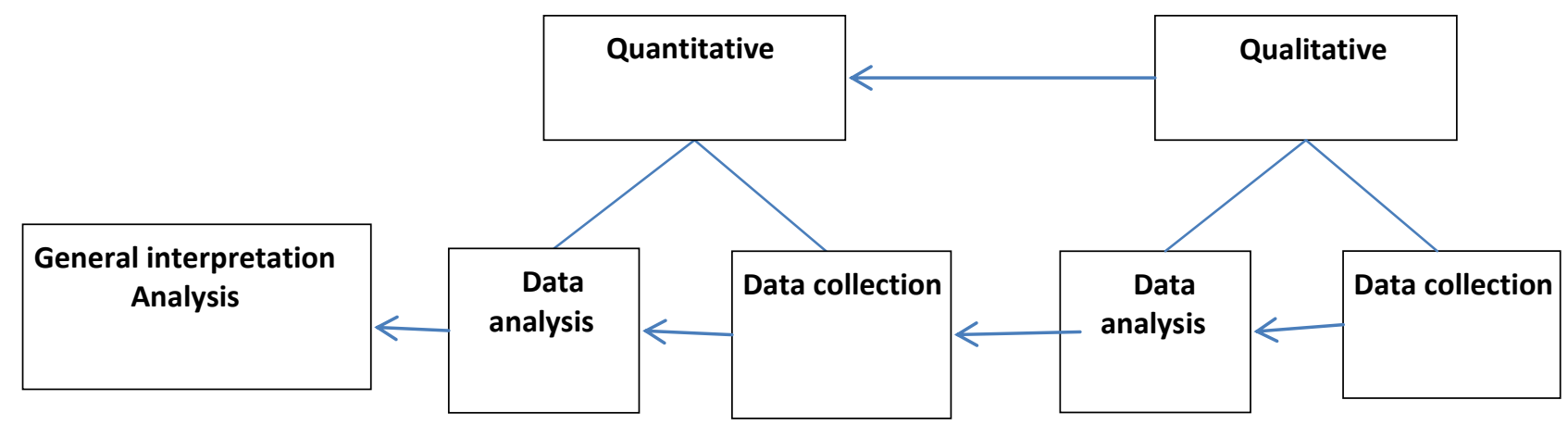

Fig. 7 The chart of exploratory stage policy 
Of course, some of them have been introduced by the respondents (snowball sampling). Scientific experts including university professors in the fields of sustainable development and ICT and professional experts were selected from industrial managers related to ICT and sustainable development. It includes administrators, professors, faculty members and experts of Environmental Protection, Institute of Environment and Sustainable Development, Faculty of Environment at Tehran University, Allameh Tabatabaei University, Faculty of Economics at Tehran University, Faculty of Electrical Engineering at Khajeh Nasir University, Ministry of Communications and Information Technology, Communication Research Center of Iran, and professors and experts from universities and research centers related to these two areas in the country. The population in the quantitative section is comprised of 73 experts from the aforementioned center in the qualitative section.

According to theoretical studies, expert consulting and interviews, 7 indicators for ICT and 8 indicators for sustainable development were extracted. 56 questions are needed in order to investigate the effect of each indicator of ICT on each of the indicators of sustainability. The questionnaire was designed on this basis. 10 sample designed questionnaires were distributed among selected individuals, and the necessary revisions have been done according to their feedbacks then reproduced and distributed in the population.

\section{RESULTS}

According to the investigation of the model presented in figures 4,5 and 6 from section 2.5 and summarizing the considerations taken into account in them following results were obtained regarding the effect of ICT on sustainable development.

1. Two main aspects of supply and demand have been considered in order to develop ICT.

2. The supply of ICT is based on three components of infrastructure (including hardware products and ICT), media (including tools and information exchange systems), and content (including text, audio, image, and video).

3. The demand for services is mainly seen in the fields of education, business, health, and government services. Therefore, the components of e-learning, e-health, and egovernment can be considered for it.

4. The main aspects of sustainable development include environment, economy, and society. Several factors are taken into account for sustainable development. Eight universal leading indicators are among them that favorably cover three mentioned dimensions.

\subsection{Sustainability Indices}

Sustainable development indices can be defined based on 8 indices. These indices have been introduced by valid international sources including universities and research centers. A full description of each index and its issuing reference is given in the corresponding source [31].

1. The index of Ecological Footprint (EF): This index is used to measure resource consumption and pollutant absorption for demographic or economic.

2. The index of Surplus Bio-capacity (SB): This index assesses the sustainability of consumption patterns. The ecological footprint of potential low fertility land surface and water are collected in order to calculate this index.
This index is a function of the amount of fertile ecological environment, consumption, and population.

3. The index of Genuine Savings (GS): This index shows net change in the total value of assets that are important for its development (such as produced assets, natural resources, environmental quality, human capital and foreign assets).

4. Environmental Vulnerability Index (EVI): This index shows the risks that threaten the environment.

5. The index of Gross Domestic Production (GDP): GDP can be considered as the total value of all goods and services produced within a country's borders, especially for a specific period of time (usually one year).

6. Human Development Index (HDI): This index represents the life expectancy at birth, access to education and acceptable standard of living.

7. Environmental Sustainability Index (ESI): This index evaluates the ability and capability of nations to protect the environment in the next several decades, and considers issues such as environmental systems, reducing environmental stresses, reducing human vulnerability to environmental pressures, social capacity, and institutional responsibility in the face of environmental challenges and global monitoring.

8. Environmental Performance Index (EPI): This index emphasizes the aspects of environmental sustainability and evaluates performance of policies and national programs to reduce environmental problems and protection of the environment and natural resources management.

\subsection{ICT Development Indices}

ICT development indices are defined with regard to theoretical studies, valid global models, and specialized advice based on the seven categories below.

1. Equipment and infrastructure products: including all physical goods and hardware.

2. Content: including all text, audio, video, maps, and etc. information that there exists the possibility to store them electronically.

3. Media: All the tools and equipment which are used to send and receive, and impart electronic content.

4. E-Government (EG): E-Government involves the use of information and communication technologies to deliver government services to citizens and businesses.

5. E-commerce (B): the purpose of the e-commerce is electronic business transactions such as sales and services on the Internet (Free and non-free services with economic purposes).

6. Electronic Health (EH): electronic health refers to all issues common to all communications and information technology and medical means. All the services that ICT offers for health are included in this area.

7. Electronic Learning (EL): E-learning includes the use of information and communication technologies in education. 


\subsection{Concluding the Indices and Providing Measurement Model}

After reviewing ICT models and models of sustainable development, a model is created which measurement indices the effect of ICT on sustainable development. Dimensions of sustainable development can be measured from three perspectives of economy, social, and environment. Eight indices were introduced to measure sustainable development in section 5.1 .

Table 2. Main dimensions of sustainable development in the sustainability assessment methods

\begin{tabular}{|c|c|c|c|}
\hline \multicolumn{3}{|c|}{ Components } & \multirow[t]{2}{*}{ Method } \\
\hline Environmen & Social & Economic & \\
\hline & $\bullet$ & & $\begin{array}{l}\text { Environmental } \\
\text { Performance Index } \\
\text { (EPI) }\end{array}$ \\
\hline$\bullet$ & $\bullet$ & & $\begin{array}{c}\text { Environmental } \\
\text { Sustainability Index } \\
\text { (ESI) }\end{array}$ \\
\hline$\bullet$ & & & $\begin{array}{c}\text { The index of } \\
\text { Ecological Footprint } \\
\text { (EF) }\end{array}$ \\
\hline & - & & $\begin{array}{c}\text { Environmental } \\
\text { Vulnerability Index } \\
\text { (EVI) }\end{array}$ \\
\hline & & $\bullet$ & $\begin{array}{c}\text { The index Gross } \\
\text { Domestic Production } \\
\text { (GDP) }\end{array}$ \\
\hline & $\bullet$ & & $\begin{array}{c}\text { Human Development } \\
\text { Index } \\
\text { (HDI) }\end{array}$ \\
\hline - & & & $\begin{array}{c}\text { The index of Surplus } \\
\text { Bio-capacity } \\
\text { (SB) }\end{array}$ \\
\hline$\bullet$ & & $\bullet$ & $\begin{array}{c}\text { The index of Genuine } \\
\text { Savings } \\
\text { (GS) }\end{array}$ \\
\hline
\end{tabular}

Based on the nature of each of these indices, it can map out the indices into economic, social or environmental dimensions. The main aspects of sustainable development in sustainability measurement methods and mapping them to triple elements are shown in Table 2. As seen in this table, some of these indices divided into two dimensions are based on their nature. For example, the net savings index (GS) has both the nature of the environmental and economic nature.

ICT and ICT development indices can be put together. In this way, there would have been indices related to ICT development and indices related to sustainable development. If the indices of sustainable development and ICT development be put together, there would have been table 4 which shows the relationship between the two according to their dimensions and components. In order to measure the impact of ICT on sustainable development model designed to explain the relation between these two areas should be mapped and the effectiveness of each of the indicators on the ICT indicators in the field of sustainable development should be investigated. Figure 8 shows the schematic of the chart mapping ICT indices and indices related to sustainable development based on parameters extracted in order to explain the effects of ICT on sustainable development model.

\subsection{Validity and Accuracy of the Proposed Model}

After determining the stability and development of ICT indices, a questionnaire consisting of 56 questions in connection with each of the dimensions of the effect of ICT on sustainable development indices was provided and was sent to 100 specialists and experts in these two areas. 73 questionnaires were returned completely and correctly. The results were investigated and the resulting comments were summarized in table 4 . The five-level Likert scale questionnaire was used as shown in table 3 .

Table 3. The weight of the answer to each question for Likert scale

\begin{tabular}{|c|c|}
\hline $\begin{array}{c}\text { Equivalent } \\
\text { value }\end{array}$ & Amount of effect \\
\hline 2 & High positive effect \\
\hline 1 & Low positive effect \\
\hline 0 & Natural \\
\hline-1 & Low negative effect \\
\hline-2 & High negative effect \\
\hline
\end{tabular}

\subsection{The Proposed Model of the Effect of ICT on Sustainable Development}

According to Table 4, the analytical model of Effects of the field of ICT in the field of sustainable development has been outlined in Figure 8. It should be noted that the weight of each effect is determined according to Table 4 . This relationship shows the effect of ICT on the eight indices of stability which can promote (positive), decrease (negative) without any effects on the relevant index.

For example, electronic commerce has significant effects on GDP growth; however, the growth of ICT products has negative effect on the ecological footprints and reduces this index. According to data obtained from the questionnaires and analyzing them, the results of table 4 show that the effect of the development of ICT on indices of social stability by a factor of 1.35 is the highest value and in the next place on the economy dimension by a factor of 1.31 and finally the least impact on environment by a factor of 1.07 .

\subsection{Suggestions for future study}

The recent research was conducted based on the eight sustainability indicators through the quantitative and qualitative approaches. The other two groups of indicators resulted from the millennium development goals and sustainable development goals were presented. Conducting the research using these indicators will provide more actual results.

The recent study can be repeated using the experimental methods i.e. instead of using the questionnaires and interviewing the experts, the data can be provided through measurement using the experimental method or the statistics and numbers presented by the related organizations. Presenting the research in this way will have more accurate results. 
Table 4. Indices of ICT development and sustainable development

\begin{tabular}{|c|c|c|c|c|c|c|c|c|c|c|c|c|}
\hline \multicolumn{12}{|c|}{ Sustainable Development } & Concepts \\
\hline \multicolumn{4}{|c|}{ environment } & \multicolumn{2}{|c|}{ Economy } & \multicolumn{4}{|c|}{ Society } & & \multirow[t]{2}{*}{ Dimensions } & \multirow{9}{*}{ 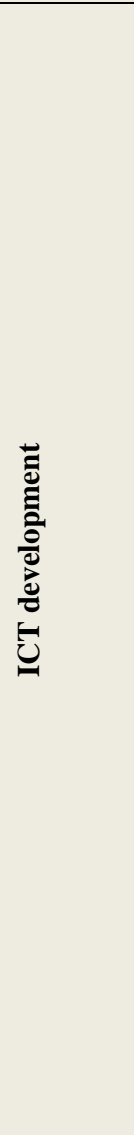 } \\
\hline 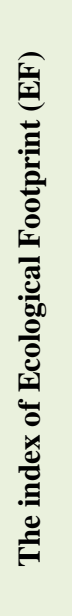 & 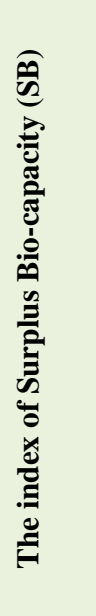 & 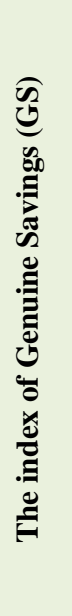 & 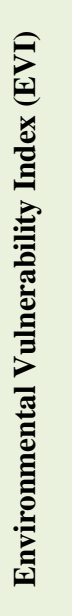 & 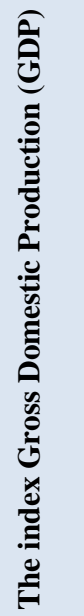 & 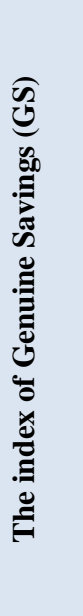 & 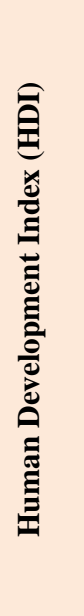 & 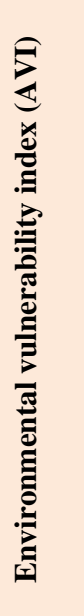 & 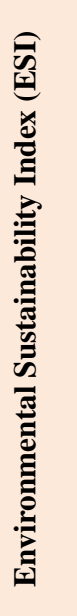 & 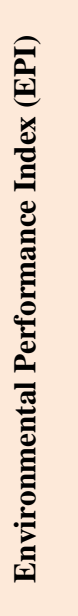 & $\begin{array}{l}\text { Components } \\
\text { and indices }\end{array}$ & & \\
\hline 0 & -0.43 & 0.71 & 1.57 & 0.57 & 0.73 & 0.57 & 1.51 & 1.15 & 1.16 & $\begin{array}{c}\text { Products } \\
\text { (Equipment - } \\
\text { Infrastructure) }\end{array}$ & \multirow{3}{*}{$\begin{array}{c}\text { Supply } \\
\text { (Production } \\
\text { and } \\
\text { product) }\end{array}$} & \\
\hline 0.86 & 0.77 & 1.19 & 1.55 & 1.11 & 1.14 & 1.13 & 1.53 & 1.17 & 1.15 & Content & & \\
\hline 0.79 & 0.75 & 1.14 & 1.67 & 1.21 & 1.18 & 1.28 & 1.67 & 1.53 & 1.23 & Media & & \\
\hline 0.14 & 1.19 & 1.59 & 1.56 & 1.43 & 1.52 & 1.49 & 1.56 & 1.44 & 1.27 & E-Government & \multirow{4}{*}{$\begin{array}{c}\text { Demand } \\
\text { (Users and } \\
\text { applications) }\end{array}$} & \\
\hline 0.14 & 1.18 & 1.58 & 1.57 & 1.46 & 1.54 & 1.48 & 1.59 & 1.14 & 1.45 & E-Commerce & & \\
\hline 0.86 & 1.12 & 1.29 & 1.44 & 1.86 & 1.20 & 1.86 & 1.46 & 1.00 & 1.14 & E-Health & & \\
\hline 0.71 & 1.26 & 1.24 & 1.41 & 1.86 & 1.28 & 1.89 & 1.43 & 1.23 & 1.27 & E-Learning & & \\
\hline \multicolumn{4}{|c|}{1.03} & & & \multicolumn{4}{|c|}{1.34} & \multicolumn{3}{|c|}{ The average effect of indices } \\
\hline
\end{tabular}

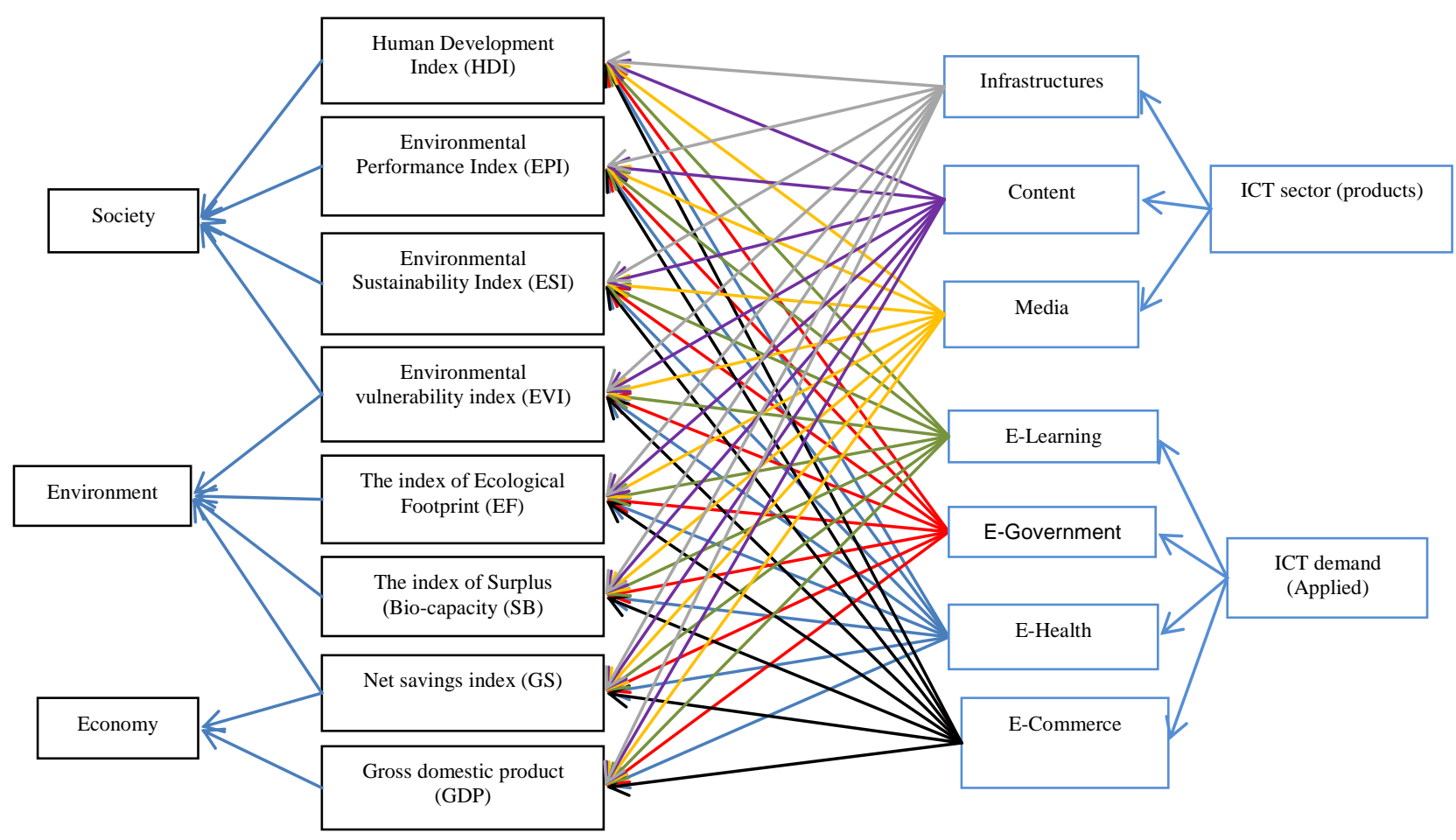

Fig. 8: The analytical model of the effect of ICT on the field of sustainable development 


\section{ACKNOWLEDGMENTS}

I appreciate my supervisor and senior advisor for their compassion and patience in the process of study and preparation of this article.

\section{REFERENCES}

[1] Zahedi, Sh. (2012). Sustainable Development. Tehran: SAMT.

[2] Khatoonabadi, A. (2001). Aspects of sustainable development from idea to action. Esfahan: Esfahan Industrial University Jihad.

[3] Sharifi, A. Ghavamifar, A. Fasanqari, M. (2014). Design and development of IT-based architecture. Tehran: Paeiz Publications.

[4] Azadnia M, Piri M. (2014). Providing a model for measuring the impact of ICT on the environment. International Conference on Development and Business Excellence, Tehran. Tehran: CIVILICA; p. 6.

[5] Houghton, J. (2010). Icts and the environment in developing countries: Opportunities and developments. The development dimension ICTs for development improving policy coherence: improving policy coherence, 149.

[6] Berkhout, F., \& Hertin, J. (2001). Impacts of information and communication technologies on environmental sustainability: Speculations and evidence. Report to the OECD, Brighton, 21.

[7] Ja'fari Samimi, A. Chehreqany, A. (2013). Ethical economy and history of economic thought. Hamedan: Nourelm.

[8] Shiri, B. (2006). ICT strategy and economic development. Tadbir, 172(14), 31-34.

[9] Moshiri, S., Jahangard, S. (2004). Information and Communication technology and economic growth of Iran. Iranian Journal of Economic Research, 6(19), 5578.

[10] Dedrick, J., Gurbaxani, V., \& Kraemer, K. L. (2003). Information technology and economic performance: A critical review of the empirical evidence. $A C M$ Computing Surveys (CSUR), 35(1), 1-28.

[11] Amin Pour, F. (2007). E-learning in universities and higher education institutions. Ketab Quarterly, 1(69), 217-228.

[12] Oliner, S. D., \& Sichel, D. E. (2000). The resurgence of growth in the late 1990s: is information technology the story?

[13] Nour, S. S. O., \& Satti, S. (2002, October). The Impact of ICT on Economic Development in the Arab World: A comparative study of Egypt and the Gulf countries. Economic Research Forum.

[14] Dewan, S., \& Kraemer, K. L. (2000). Information technology and productivity: evidence from countrylevel data. Management Science, 46(4), 548-562.

[15] Lee, M. I. H., \& Khatri, M. Y. (2003). Information technology and productivity growth in Asia (No. 3-15). International Monetary Fund.
[16] Papaioannou, S. K. (2004). FDI and ICT Innovation Effect on productivity growth: A Comparison between developing and developed countries. Athens University of Economics and business, Athens, Greece.

[17] Oulton, N., \& Srinivasan, S. (2005). Productivity growth and the role of ICT in the United Kingdom: an industry view, 1970-2000. Centre for Economic Performance, London School of Economics and Political Science.

[18] Kettenē, E. (2006). Economic Growth, Productivity and Technological Change (Doctoral dissertation, SD). http://lekythos.library.ucy.ac.cy/handle/10797/5844

[19] Mouelhi, R. B. A. (2009). Impact of the adoption of information and communication technologies on firm efficiency in the Tunisian manufacturing sector. Economic Modelling, 26(5), 961-967.

[20] Asari Arani, A., Aghaei Khoundabi, M. (2008). The impact of ICT on economic growth in OPEC. Journal of Economic Research, 8(2), 63-82.

[21] Najarzadeh, R., Aghaei Khondabi, M., Tal'ati, M., The effect of ICT on economic growth in member countries of the Organization of Islamic Conference (OIC). Journal of Business Research, 11(44), 49-78.

[22] Asghar Poor, H., Mohammadzadeh, P., Jalil Poor, S. (2011). Studying the Impact of Developmental Indicators on ICT Use in Selected Asian Countries. Journal of Regional Economic and Development. 1(1), 22-51.

[23] Faghih Nasiri, M., Goudarzi, A. (2005). Investigating the effects of ICT and economic growth in selected countries panel data method. Modern Economics and Business Journa, 3(22), 73-94

[24] Pajouyan, G., Moradhasel, N. (2007). Investigating the effect of Economic Growth on Air pollution. Journal of economic research, 4, 141-160.

[25] Pourkazemi, M. H., Ebrahimi, E. (2008). Investigating Environmental Kuznets Curve in Middle East. Iranian Journal of Economic Research, 34, 57-71.

[26] Asgharpour, H., Mousavi, S. (2009). Testing Environmental Kuznets hypothesis: Use of Consolidated Collective technic. Journal of Economic Science, 3.

[27] Plepys, A. (2002). The grey side of ICT. Environmental Impact Assessment Review, 22(5), 509-523.

[28] Sadipour A. (2011). Investigating the effects of ICT on carbon dioxide emissions. Iran: Islamic Azad University, 105-107.

[29] Yi, L., \& Thomas, H. R. (2007). A review of research on the environmental impact of e-business and ICT. Environment international, 33(6), 841-849.

[30] Creswell, J. W. (2013). Research design: Qualitative, quantitative, and mixed methods approaches. Sage publications.

[31] Farzam Pour, A., Sangachin, A., Salehi, M. R. (2010). Comparison of analytical comparative assessment of sustainable development. Journal of Environmental Research, 1(1), 67-82. 